Maria Karollyna do N. Silva Leandro, Janaína E. Rocha, Camila F. Bezerra, Priscilla R. Freitas, Jessica Horana F. Feitosa, Viviane B. Bezerra, Rizelle de O. Barros, Livia Maria G. Leandro, José Junior dos S. Aguiar, Paulo S. Pereira, Marcela Christofoli, Jaime Ribeiro-Filho, Marcello Iriti*, Henrique Douglas M. Coutinho and Edinardo Fagner F. Matias

\title{
Modulation of antibiotic resistance by the essential oil of Ocimum gratissimum L. in association with light-emitting diodes (LED) lights
}

https://doi.org/10.1515/znc-2020-0034

Received February 17, 2020; accepted June 4, 2020

\begin{abstract}
This study aimed to evaluate the antibacterial and antibiotic-enhancing effects of the essential oil obtained from Ocimum gratissimum L. (OEOg) alone or in association with light-emitting diodes (LED) lights. The essential oil was obtained by hydrodistillation and its chemical composition analysed by gas chromatography coupled to mass spectrometry. The antibacterial and antibiotic-enhancing activities against multiresistant strains of Staphylococcus aureus and Escherichia coli were evaluated by the gaseous contact method. The analysis of the photoinductive effect on the antibacterial activity of the OEOg and antibiotics was assessed through exposure to different LED lights (red, blue and yellow). The phytochemical analysis identified five
\end{abstract}

\footnotetext{
*Corresponding author: Marcello Iriti, Department of Agricultural and Environmental Sciences, Milan State University, via G. Celoria 2,

20133, Milan, Italy, E-mail: marcello.iriti@unimi.it. https://orcid.org/ 0000-0002-5063-1236

Maria Karollyna do N. Silva Leandro: Laboratory of Microbiology and Molecular Biology - LMBM, Regional University of Cariri- URCA, Crato, Ceara, Brazil; Leão Sampaio University Center - Unileão, Juazeiro do Norte, Ceara, Brazil

Janaína E. Rocha, Camila F. Bezerra, Priscilla R. Freitas and Henrique Douglas M. Coutinho: Laboratory of Microbiology and Molecular Biology - LMBM, Regional University of Cariri- URCA, Crato, Ceara, Brazil

Jessica Horana F. Feitosa, Viviane B. Bezerra, Rizelle de O. Barros, Livia Maria G. Leandro and José Junior dos S. Aguiar: Leão Sampaio University Center - Unileão, Juazeiro do Norte, Ceara, Brazil

Paulo S. Pereira: Goiano Federal Institute - IFGOIANO - Campus Rio Verde, Rio Verde, Goias, Brazil

Marcela Christofoli: Postgraduate Program in Biotechnology and Biodiversity - Rede Pro-Centro Oeste - UFG, Goiania, Goias, Brazil Jaime Ribeiro-Filho: Gonçalo Moniz Institute, Oswaldo Cruz Foundation (IGM-FIOCRUZ/BA), Salvador, Bahia, Brazil Edinardo Fagner F. Matias: Caririense Graduation Center, Juazeiro do Norte, Ceara, Brazil
}

compounds, including eugenol, as the major constituent. The OEOg caused a significant inhibition of the halo, indicating a direct antibacterial effect. Exposure to the LED lights significantly enhanced the activity of the OEOg against $E$. coli. On the other hand, the action of the essential oil against $S$. aureus was enhanced by exposure to both blue and yellow lights. The effects of LED light exposure on the activity of conventional antibiotics varied significantly according to the drug and the bacterial strain. However, most combinations of LED lights and the OEOg presented synergistic effects against resistant bacterial strains, indicating enhanced antibacterial activity. Thus, these in vitro findings suggest that both OEOg and LED lights have promising antibacterial effects. Nevertheless, further research is required to evaluate in vivo the potential of these therapies for the treatment of infectious skin diseases.

Keywords: bacterial resistance; enhanced antibiotic activity; LED lights; Ocimum gratissimum.

\section{Introduction}

The use of plants in folk medicine constitutes a practice that is passed down from generation to generation. Through this ancient practice, empirical knowledge has been shared, learned and internalised among different cultures [1], contributing significantly to the use of extracts and isolated components in scientific research. Nevertheless, therapeutic applications involving bioactive compounds require studies proving their effectiveness and safety [2-4].

Ocimum gratissimum L. is a plant popularly known as 'alfavaca'. This species is traditionally used for the treatment of rheumatism, mental illness, influenza, cough, pruritus, stress, indigestion, flatulence, headache, fatigue, as well as sedative and expectorant [5, 6]. Previous research has demonstrated that biologically active extracts 
and essential oils obtained from 0 . gratissimum present anti-inflammatory, antiseptic, antifungal and antibacterial activities, indicating that this species has the potential to be used in the treatment of infections [7, 8]. While essential oils play a crucial role in the protection and survival of plants, increasing evidence indicates that these substances have remarkable therapeutic potential [2-4].

Antibiotic resistance represents a significant threat to human health [9]. Resistant bacteria are capable of causing a spectrum of manifestations ranging from mild infections to severe diseases. Nevertheless, skin infections represent a major health problem due to their impact on the quality of life of patients [10]. Additionally, according to the Brazilian Society of Dermatology (SBD), skin diseases are among the leading conditions requiring the use of health services [11]. As the emergence of resistant bacteria has limited the treatment of skin infections with conventional antibiotics, the search for new therapies to combat bacterial resistance have a significant impact on public health research. In this context, plant derived natural products, including extracts, essential oils and isolated secondary metabolites have demonstrated the ability to enhance the activity of antibiotics against resistant bacterial strains [9].

In addition to the use of natural products and new synthetic drugs, studies have reported the therapeutic potential of light-emitting diodes (LED). LED devices have been commonly used as a phototherapeutic tool in the treatment of dermatological lesions. Accordingly, previous research has reported that, in addition to presenting antimicrobial properties, LED lights can optimise the penetration of systemic drugs due to a vasodilator action [12]. Moreover, both experimental and clinical studies have demonstrated that due to their photoinductive effects, LED lights have the potential to be used in a wide variety of clinical conditions $[13,14]$.

Therefore, this study aimed to evaluate the antibacterial and antibiotic-enhancing effects of the essential oil obtained from $O$. gratissimum L. (OEOg) alone or in association with LED lights.

\section{Methodology}

\subsection{Collection and identification of the botanic material}

The leaves of $O$. gratissimum L. were collected in a private property located at a region known as 'Chapada do Araripe' in the municipality of Crato, Ceará, Brazil. A voucher specimen was prepared and registered at the Herbarium Dárdano Andrade Lima of the Regional University of Cariri (registry number 3978).

\subsection{Essential oil extraction}

The essential oil of 0 . gratissimum L. was extracted by hydrodistillation in a Clevenger type apparatus. Briefly, $500 \mathrm{~g}$ of leaves was crushed and subjected to extraction with $2.5 \mathrm{~L}$ of distilled water at boiling temperature for $2 \mathrm{~h}$. After extraction, the essential oil, which presented a yield of $0.2 \%$, was added with anhydrous sodium sulphate $\left(\mathrm{Na}_{2} \mathrm{SO}_{4}\right)$ and stored under refrigeration $\left(-4^{\circ} \mathrm{C}\right)$ for preservation [15].

\subsection{Identification of chemical components}

The analysis of the chemical constituents of the essential oil was carried out using a GCMS System (TQ8030 Shimadzu) in the Laboratory of Chemistry of Natural Products of the Federal University of São Carlos (UFSCar). Separation was performed on a fused-silica capillary column RTX-5MS (30 m $\times 0.25 \mathrm{~mm}$ id, $0.25 \mu \mathrm{m}$ film thickness, Restek) using ultra-high purity helium as a carrier gas at a flow rate of $3.0 \mathrm{~mL} / \mathrm{min}$. The mass spectrometer was operated in the electron impact mode (EI) at $70 \mathrm{eV}$, scanning at a range of 43-550 $\mathrm{m} / \mathrm{z}$. The ion source temperature was set at $230^{\circ} \mathrm{C}$. The separation data were analysed using the GCMS Real Time Analysis ${ }^{\circledR}$ Software. The temperature was initially maintained at $60^{\circ} \mathrm{C}$ for $3 \mathrm{~min}$, followed by an increase of $3{ }^{\circ} \mathrm{C} / \mathrm{min}$ until reaching $200^{\circ} \mathrm{C}$. Next, temperature was programmed to increase $15^{\circ} \mathrm{C} / \mathrm{min}$ until reaching $280{ }^{\circ} \mathrm{C}$, which was maintained for $1 \mathrm{~min}$. The apparatus settings were as follows: Injection temperature: $230{ }^{\circ} \mathrm{C}$, detection temperature: $300^{\circ} \mathrm{C}$, injection pressure: $57.4 \mathrm{KPa}$, Splitless ratio: 150 , detection range of the mass spectrometer: $43-550 \mathrm{~m} / z$; start time (cut time of the solvent): $3.0 \mathrm{~min}$ and flow $3 \mathrm{~mL} / \mathrm{min}$. The identification of the oil components was based on the Kovats retention index, calculated in relation to the retention times of a homologous series of n-alkanes (C-7 to C-40) and based on the fragmentation pattern observed in mass spectra by comparing them with the literature data and the Nist spectra [16].

\subsection{Materials}

Amikacin (30- $\mu \mathrm{g}$ disks), gentamicin (10- $\mu \mathrm{g}$ disks), norfloxacin $(10-\mu \mathrm{g}$ disks), ciprofloxacin (5- $\mu \mathrm{g}$ disks), penicillin $\mathrm{G}(10-\mu \mathrm{g}$ disks) and oxacillin (1- $\mu \mathrm{g}$ disks) were used as standard antibiotics and purchased from Sigma ${ }^{\circledR}$. Agar heart infusion (HIA) and Brain Heart Infusion (BHI) agar culture media were purchased from HIMEDIA. The LED device (brand NEW Estética ${ }^{\circledR}$ ) was used in the photoinduction protocols. This device can emit the red, blue and 
yellow light spectra, as well as combinations of these lights. The following lights were used in the experiments: blue (with a wavelength pre-determined by the apparatus of $415 \mathrm{~nm})$, red $(620 \mathrm{~nm})$ and yellow $(590 \mathrm{~nm})$. These lights were applied at a distance of $1.5 \mathrm{~cm}$ from the plates.

\subsection{Microorganisms}

This study used multidrug resistant strains of Escherichia coli 06 and Staphylococcus aureus 358, which were obtained from clinical isolates. Both strains were maintained in heart infusion agar (HIA) medium and, for testing, samples were transferred from the solid medium to test tubes containing sterile saline, and turbidity was assessed using a value of 0.5 on the McFarland scale, corresponding to $10^{8} \mathrm{CFU} / \mathrm{mL}$. The resistance profile of the bacterial strains is shown in Table 1 .

\subsection{Evaluation of the antibacterial and antibiotic-enhancing activities by gaseous contact}

The bacteria were sown in Petri dishes containing BHI agar. Disks of antibiogram-like filter paper were placed in the centre of each plate, and $10 \mu \mathrm{L}$ of the essential oil was added to the plate lid. For determination of the inhibition halos, the plates were incubated in the oven at $37^{\circ} \mathrm{C}$ for $24 \mathrm{~h}$. The tests were performed in triplicate, and a millimetre ruler was used to determine the halos (Table 2).

The evaluation of the antibiotic-enhancing activity by gaseous contact was performed in Petri dishes containing BHI as previously described [17] with adaptations. The plates were inverted, and then $10 \mu \mathrm{L}$ of the essential oil was added in the lids allowing the interaction with the antibiotic disks from the volatilisation. Alternatively, plates were prepared in the absence of the essential oil for further comparison between plates containing antibiotics

Table 1: Bacterial origin and antibiotic resistance profile.

\begin{tabular}{llc}
\hline Bacteria & Origin & Resistance profile \\
\hline Staphylococcus & Surgical & Oxa, Gen, Tob, Ami, Neo, \\
aureus SA358 & wound & Para, But, Sis, Net \\
Escherichia coli & Urine & Cf, Ca, Clx, Amp, Nor, \\
EC 06 & & Lm, Cip, Lv, Of, Ampisul \\
\hline
\end{tabular}

Amp - Ampicillin; Ampisul - Ampicillin-sulbactam; Ami - Amikacin; Ca - Cefadroxil; Cf - Cephalothin; Clx - Cephalexin; Cip - Ciprofloxacin; Lm - Lomefloxacin; Lv - Levofloxacin; Tob - Tobramycin; Of - Ofloxacin; Oxa - Oxacillin; Gen - Gentamycin; Nor - Norfloxacin; Neo - Neomycin; Para - Paramomycin; But - Butyrosine; Sis - Sisomycin; Net - Netilmicin.
Table 2: Chemical composition of essential oil from Ocimum gratissimum leaves.

\begin{tabular}{lrr}
\hline Compounds & Retention time (min) & (\%) \\
\hline 1,8-cineole & 8.60 & 35.61 \\
$(E)$ - $\beta$-Ocimene & 8.68 & 2.89 \\
Eugenol & 21.86 & 52.02 \\
$(E)$-Caryophyllene & 24.42 & 4.37 \\
$\alpha$-Guaiene & 27.07 & 5.11 \\
Total & - & $\mathbf{1 0 0 . 0 0}$ \\
\hline
\end{tabular}

exclusively and the plates containing antibiotics and the essential oil. For determination of the inhibition halos, the plates were incubated in an oven at $37^{\circ} \mathrm{C}$ for $24 \mathrm{~h}$. The tests were performed in triplicate, and a millimetre ruler was used to determine the inhibition halos.

\subsection{Evaluation of the antibiotic-modulating activity in association with LED light exposure}

In this experimental protocol, bacterial cultures and treatments were performed as described for the evaluation of antibacterial and antibiotic-enhancing activities by gaseous contact. To evaluate the effects of LED light exposure, the plates were exposed to red, blue or yellow light for $20 \mathrm{~min}$ and then incubated at $37^{\circ} \mathrm{C}$ for $24 \mathrm{~h}$. The tests were performed in triplicate and results were analysed as described above.

\subsection{Statistical analysis}

Data are expressed as arithmetic means \pm standard deviations and were analysed by analysis of variance (ANOVA), followed by Bonferroni's post-test using GraphPad Prism software. Statistical significance was considered when $p<0.05$ [18].

\section{Results}

The chemical analysis of the essential oil of 0 . gratissimum revealed the presence of five major compounds: (E)- $\beta$-ocimene (2.89\%; Hydrocarbon monoterpene), (E)-caryophyllene (4.37\%; Hydrocarbon sesquiterpene), $\alpha$-guaiene (5.11\%; Hydrocarbon sesquiterpene), 1,8-cineole (35.61\%; Oxygenated sesquiterpene) and eugenol (52.02\%; Phenylpropanoid). 
The analysis of the antibacterial effect of OEOg by gaseous contact demonstrated a significant reduction of the halo, indicating that the chemical compounds of the essential oil volatilised and were absorbed by the filter paper and inhibiting bacterial growth.

Exposure to LED lights significantly enhanced the antibacterial effects of the OEOg against $E$. coli. Blue, red and yellow lights caused inhibitions of bacterial growth corresponding to $35.4,28.5$ and $53.4 \%$, respectively, compared to the control. On the other hand, the experiments with $S$. aureus revealed that while exposure to the red light improved the antibacterial effect of the essential oil, exposure to blue and yellow lights increased the halo in 42.6 and $29.4 \%$, respectively, demonstrating an antagonistic effect (Figure 1).

Following the promising antibacterial effects demonstrated by the OEOg alone, or in combination with some LED lights, this study evaluated the ability of these treatments to modulate bacterial resistance in association with standard antibiotics. The OEOg and amikacin treatments caused similar inhibition of the growth of both strains. Exposure to LED lights did not increase the antibacterial effect of amikacin. However, when this antibiotic was simultaneously combined with the OEOg and red light, a significant increase of the halo in $E$. coli plates was observed. On the other hand, in experiments with S. aureus, combination with each of the three lights and the essential oil potentiated the antibacterial effect of amikacin, indicating a synergistic effect (Figures 2 and 3).

The analysis of the antibiotic-enhancing activity using gentamicin (Figures 4 and 5), demonstrated that the association of OEOg with LED lights significantly enhanced the antibacterial effect of this antibiotic, when compared with the group exposed to gentamicin alone against $S$. aureus. No significant differences were observed between treatments with the antibiotic alone and the treatment with the antibiotic associated with the oil. On the other hand, in the tests with E. coli, the association with OEOg and LED did not affect the activity gentamicin.

The experiments using ciprofloxacin (Figures 6 and 7) revealed that this standard drug caused more significant inhibition of bacterial growth in comparison with the OEOg against both bacterial strains. No significant difference between the combined treatments against $E$. coli was found. However, against $S$. aureus, the association between the essential oil and yellow or red light decreased the antibacterial effect of ciprofloxacin, indicating an antagonistic effect as attested by a decrease of the inhibition halo. No relevant difference between other treatment groups was found.

As shown in Figures 8 and 9, the inhibition halo observed in the norfloxacin group was significantly higher than the halo of the OEOg against both strains, indicating a more potent antibacterial activity by the antibiotic. The test with $E$. coli revealed that the simultaneous association with the oil and LED lights did not change the antibacterial effect of ciprofloxacin. Similar findings were obtained for the association of the oil with blue and yellow lights against S. aureus. However, when the oil was associated with the red light against this strain, an antagonistic effect was observed. An antagonistic effect was also observed when the antibiotic was associated with the OEOg in the absence of LED light exposure. No relevant difference between other treatment groups was observed.

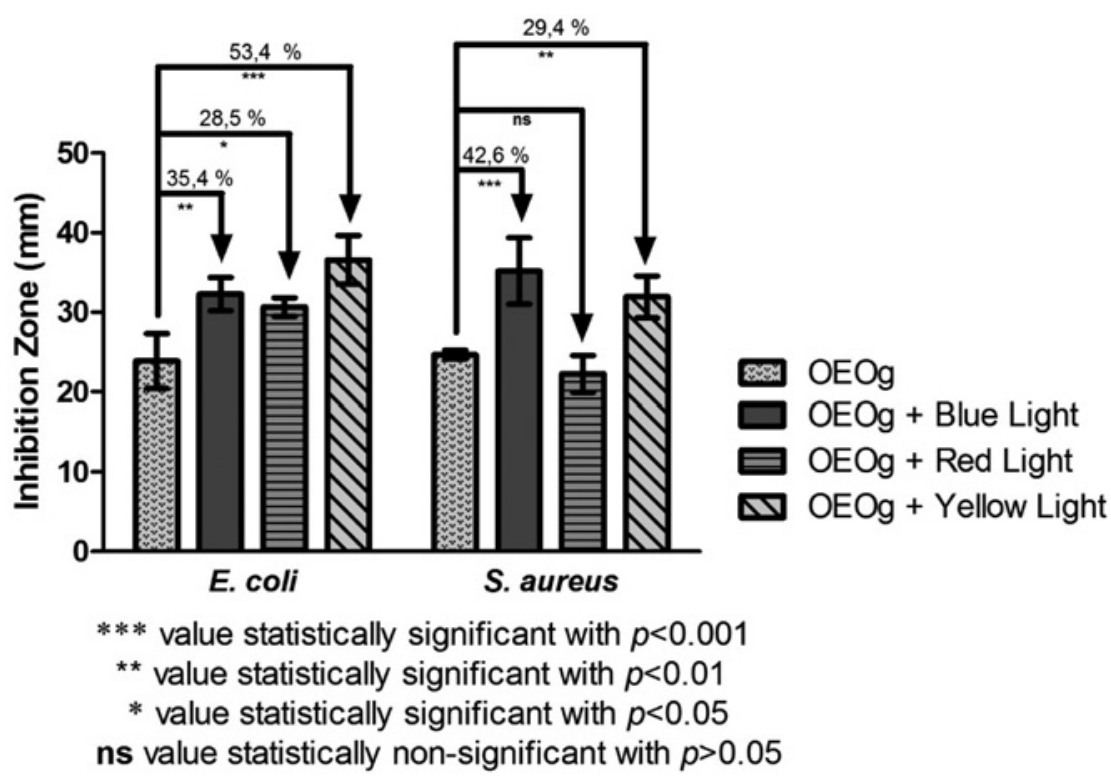

Figure 1: Effect of the association between OEOg and light-emitting diodes (LED) lights on bacterial growth. 


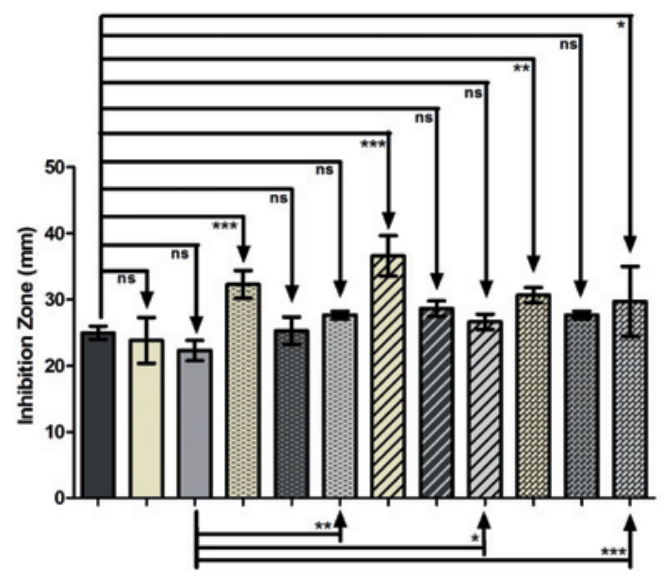

Amikacin

$\square$ OEOg + Amikacin

OEOg + Blue Light

Amikacin + Blue Light

OEOg + Amikacin + Blue Light

ש OEOg + Yellow Ligth

II Amikacin + Yellow Ligth

Z OEOg + Amikacin + Yellow Ligth

OEOg + Red Light

Amikacin + Red Light

OEOg + Amikacin + Red Light

*** value statistically significant with $p<0.001$

** value statistically significant with $p<0.01$

- value statistically significant with $p<0.05$

ns value statistically non-significant with $p>0.05$

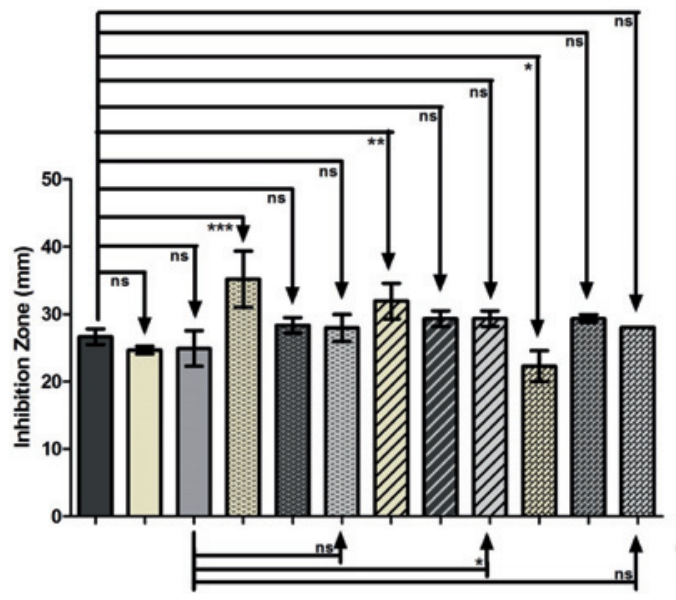

Amikacin

$\square$ OEOg

$\square$ OEOg + Amikacin

OEOg + Blue Light

.6. Amikacin+ Blue Light

OEOg + Amikacin + Blue Light

E OEOg + Yellow Ligth

I. Amikacin + Yellow Ligth

ש] OEOg + Amikacin + Yellow Ligth

OEOg + Red Light

Amikacin + Red Light

OEOg + Amikacin + Red Light

*** value statistically significant with $p<0.001$ ** value statistically significant with $p<0.01$

* value statistically significant with $p<0.05$

ns value statistically non-significant with $p>0.05$
Figure 2: Association of OEOg with amikacin and light-emitting diodes (LED) lights against Escherichia coli.

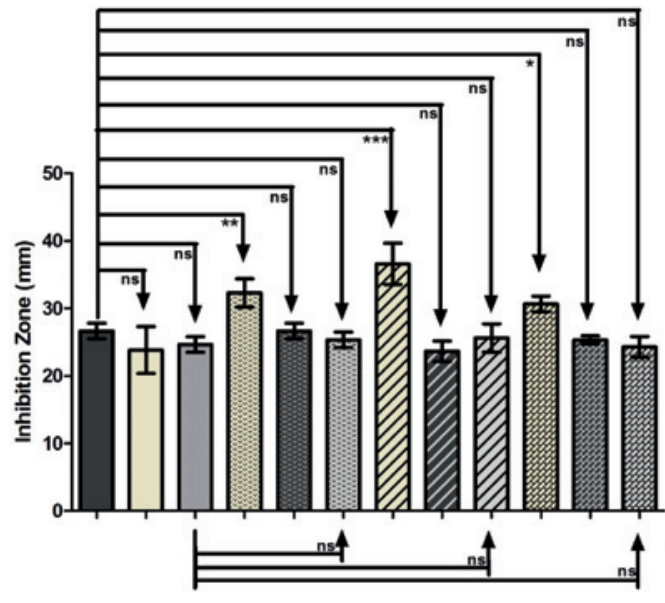

Figures 10 and 11 show the effect of different treatment associations on bacterial resistance to penicillin $\mathrm{G}$. The inhibition halo observed in the group treated with the antibiotic was more significant than that demonstrated in
Figure 3: Association of OEOg with amikacin and light-emitting diodes (LED) lights against Staphylococcus aureus.
Figure 4: Association of OEOg with Gentamicin and light-emitting diodes (LED) lights against Escherichia coli. the group treated with the OEOg against $E$. coli. However, no difference between these groups against $S$. aureus was found. The combination of the essential oil and LED lights did not affect the activity of the antibiotic against $E$. coli. 


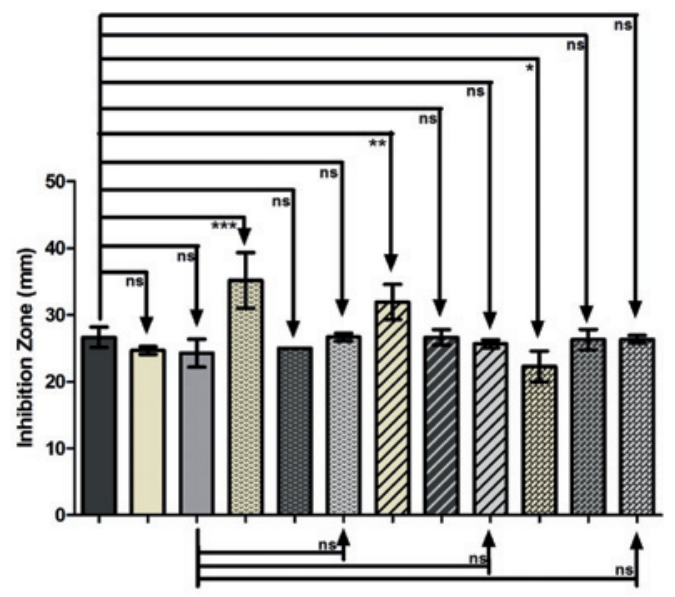

$\square$ Gentamicin

$\square$ OEOg

OEOg + Gentamicin

OEOg + Blue Light

Gentamicin + Blue Light

OEOg + Gentamicin + Blue Light

Z7 OEOg + Yellow Ligth

ש. Gentamicin + Yellow Ligth

E OEOg + Gentamicin + Yellow Ligth

OEOg + Red Light

mentamicin + Red Light

was OEO + Gentamicin + Red Light

*** value statistically significant with $p<0.001$

** value statistically significant with $p<0.01$

* value statistically significant with $p<0.05$

ns value statistically non-significant with $p>0.05$

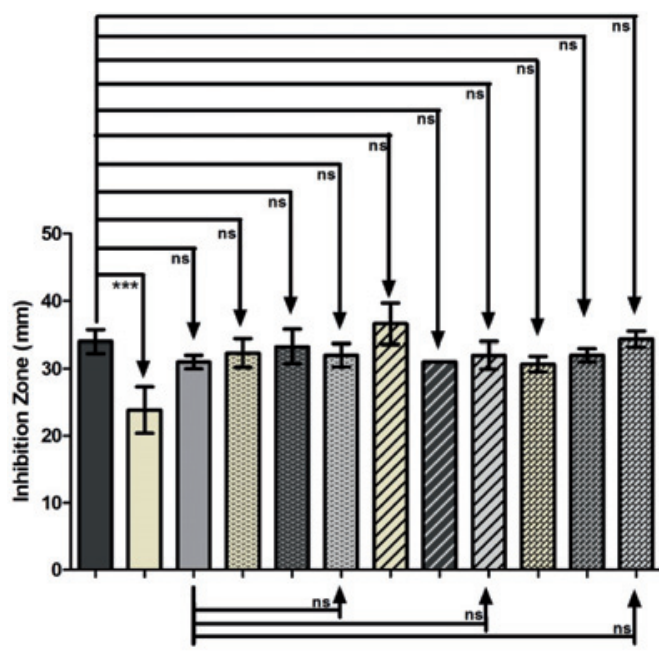

Ciprofloxacin

$\square$ OEOg

$\square$ OEOg + Ciprofloxacin

OEOg + Blue Light

Ciprofloxacina + Blue Light

OEOg + Ciprofloxacin + Blue Light

ש OEOg + Yellow Ligth

20 Ciprofloxacin + Yellow Ligth

ש7 OEOg + Ciproflox + Yellow Ligth

OEOg + Red Light

Ciprofloxacin + Red Light

OEOg + Ciprofloxacin + Red Light

*** value statistically significant with $p<0.001$ ns value statistically non-significant with $p>0.05$

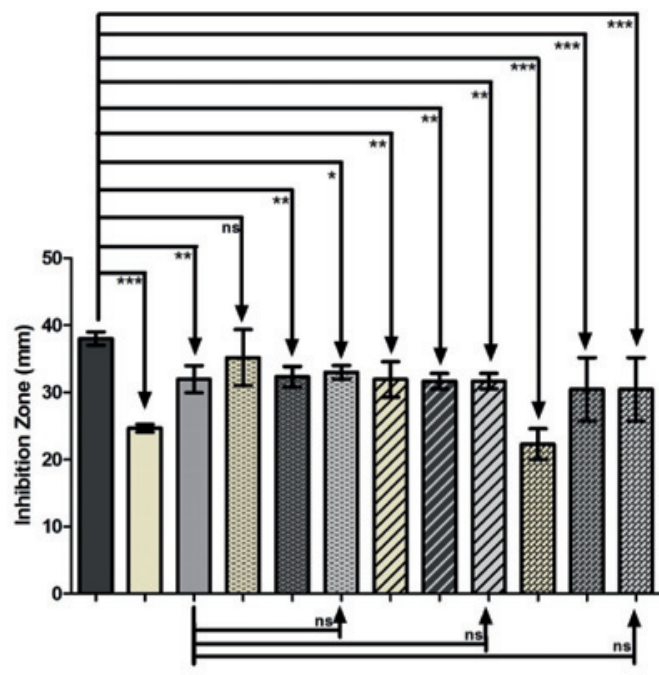

Ciprofloxacin

$\square$ OEOg

$\square$ OEOg + Ciprofloxacin

OEOg + Blue Light

Ciprofloxacin + Blue Light

OEOg + Ciprofloxacin + Blue Light

ש] OEOg + Yellow Ligth

II Ciprofloxacin + Yellow Ligth

ש OEOg + Ciprofloxacin + Yellow Ligth

OEOg + Red Light

Ciprofloxacin + Red Light

OEOg + Ciprofloxacin + Red Light

*** value statistically significant with $p<0.001$

"* value statistically significant with $p<0.01$

* value statistically significant with $p<0.05$

ns value statistically non-significant with $p>0.05$
Figure 5: Association of OEOg with Gentamicin and light-emitting diodes (LED) lights against Staphylococcus aureus.

Figure 6: Association of OEOg with Ciprofloxacin and light-emitting diodes (LED) lights against Escherichia coli.
Figure 7: Association of OEOg with Ciprofloxacin and light-emitting diodes (LED) lights against Staphylococcus aureus. 
However, the combination of the OEOg with blue or yellow lights significantly enhanced the activity of penicillin $\mathrm{G}$ against $S$. aureus compared with the drug alone. Interestingly, while the association with the essential oil did not affect the action of the antibiotic, the association with each of the three LED lights decreased the activity of this drug against $E$. coli. Similar findings were observed for the association with the blue light against $S$. aureus.

Finally, the antibacterial analysis using oxacillin as a standard antibiotic found no differences between its antibacterial activity and the effect of the OEOg and against E. coli and S. aureus (Figures 12 and 13). A comparison between the effect of the antibiotic alone and the antibiotic simultaneously associated with the essential oil and LED lights demonstrated that the combined treatment between the oil and blue or yellow lights enhanced the activity of the antibiotic against broth strains. The association with OEOg alone did not affect the action of oxacillin against both strains. While the association with LED lights did not affect the effectiveness of this antibiotic to E. coli, association with yellow and red lights enhanced the antibiotic activity against $S$. aureus. No significant differences between the other treatment groups were found.

\section{Discussion}

The chemical analysis of the OEOg revealed the presence of eugenol and 1,8-cineole as major constituents. Previous research has demonstrated that both compounds present antibacterial effects. Studies have suggested that due to its hydrophobic properties, eugenol can cause a separation of the lipids in both the cell and mitochondrial membranes, affecting the structure and permeability of bacterial membranes. Moreover, it has been suggested that the antibacterial action of this compound is also associated with proton-pump inhibition, leading to disturbed electron flow and impaired active transport, which could lead to coagulation of the cell content [19]. Accordingly, Sokovic and collaborators reported that 1,8-cineole exerts remarkable antimicrobial activities, acting as a bacteriostatic and bactericidal compound [20]. These findings support the hypothesis that the essential oil of $O$. gratissimum could constitute a source of bioactive compounds with the potential to combat infections caused by resistant bacteria.

The evaluation of the antibacterial action of the OEOg by gaseous contact demonstrated that the volatilised essential oil induced the formation of a significant inhibition halo formation against resistant strains of $S$. aureus and $E$. coli, which could be attributed to the presence of the major compounds eugenol and 1,8 cineole, whose antibacterial properties have been previously reported [20, 21]. According to the Food and Agriculture Organization (FAO) and the World Health Organization (WHO), a daily dose of eugenol of $2.5 \mathrm{mg} / \mathrm{kg}$ of body weight is considered safe, non-carcinogenic and non-mutagenic for humans [22]. The findings of the present study are corroborated by previous research reporting the antibacterial effects of four different extracts obtained from $O$. gratissimum against $E$. coli using the disc diffusion method [23].

The tests evaluating the interaction between the OEOg and different LED lights demonstrated that the activity of the oil was potentiated by exposure to most-light types. Some evidence has suggested that LED light therapy promotes a photoinduced effect that is more effective against Gram-positive strains, since in Gram-negative bacteria, the penetration of photons may be hampered the intrinsic

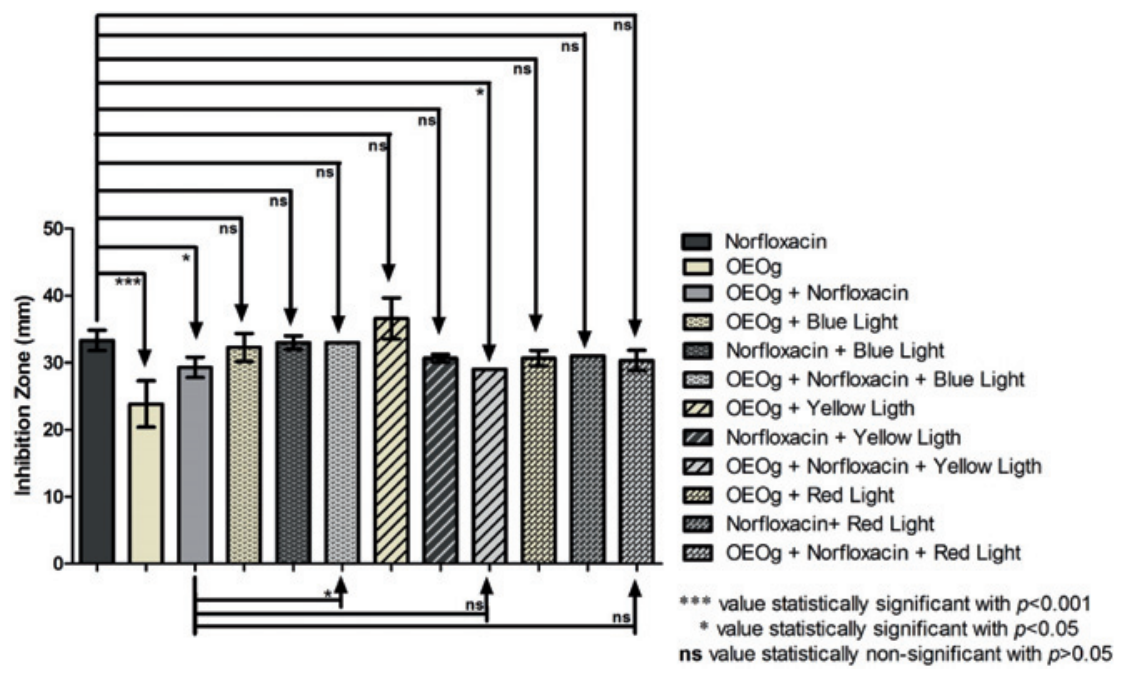

Figure 8: Association of OEOg with Norfloxacin and light-emitting diodes (LED) lights against Escherichia coli. 

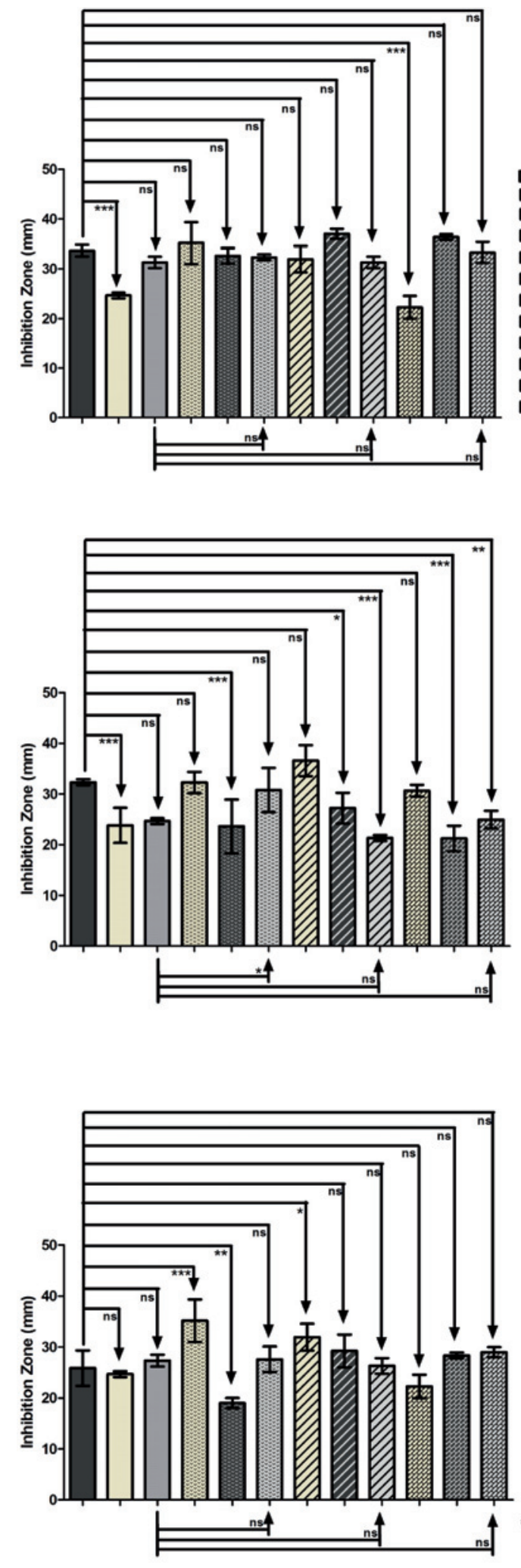

Norfloxacin

므Og

$\square \mathrm{OEOg}+$ Norfloxacin

OEOg + Blue Light

Norfloxacin + Blue Light

OEOg + Norfloxacin + Blue Light

ש] OEOg + Yellow Ligth

IV Norfloxacin + Yellow Ligth

Z OEOg + Norfloxacin + Yellow Ligth

OEOg + Red Light

Norfloxacin+ Red Light

OEOg + Norfloxacin + Red Light

**** value statistically significant with $p<0.001$ ns value statistically non-significant with $p>0.05$
Figure 9: Association of $\mathrm{OEOg}$ with Norfloxacin and light-emitting diodes (LED) lights against Staphylococcus aureus.
Figure 10: Association of OEOg with Penicilin $\mathrm{G}$ and light-emitting diodes (LED) lights against Escherichia coli. characteristics of the cell wall and membrane [24]. In contrast, the results of the present study showed that LED lights exerted promising antibacterial effects on E. coli, a
Gram-negative bacterium. Nevertheless, Bevilacqua and collaborators demonstrated that the association of LED lights with blue toluidine presented an excellent activity 


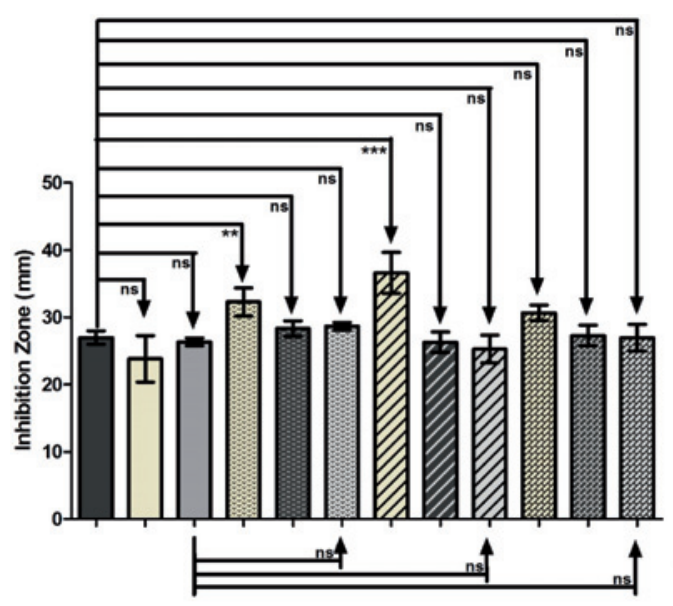

$\square$ Oxacillin

$\square$ OEOg

$\square$ OEOg + Oxacillin

OEOg + Blue Light

Oxacillin + Blue Light

OEOg + Oxacillin + Blue Light

ש OEOg + Yellow Ligth

II Oxacillin + Yellow Ligth

[D OEOg + Oxacillin + Yellow Ligth

OEOg + Red Light

Oxacillin + Red Light

OEOg + Oxacillin + Red Light

*** value statistically significant with $p<0.001$

** value statistically significant with $p<0.01$ ns value statistically non-significant with $p>0.05$
Figure 12: Association of OEOg with Oxacilin and light-emitting diodes (LED) lights against Escherichia coli.

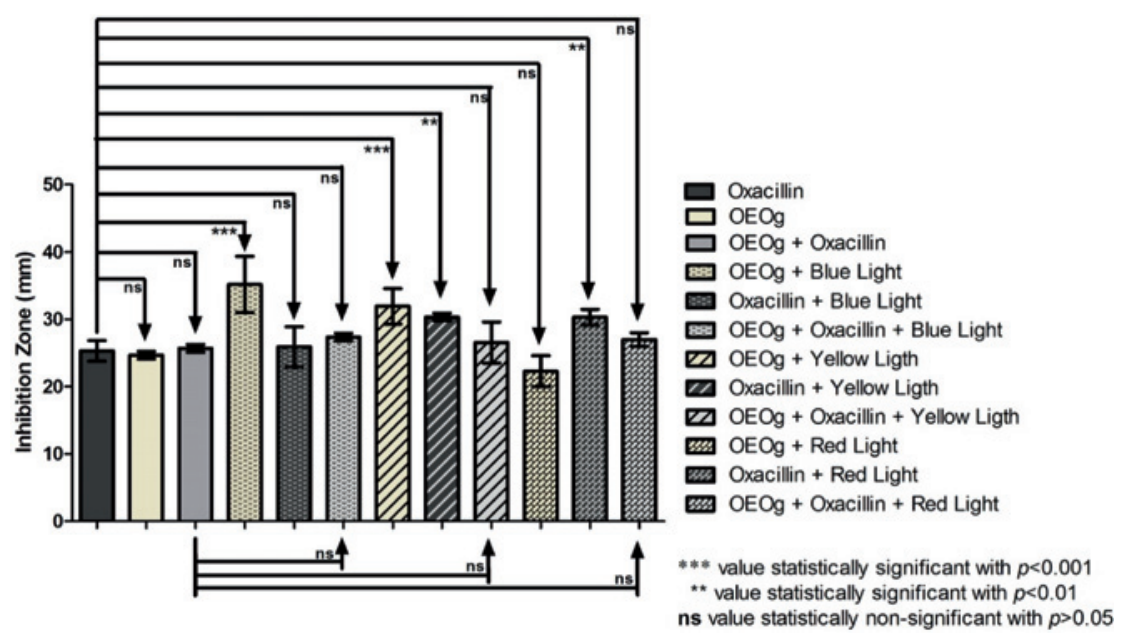

Figure 13: Association of OEOg with Oxacilin and light-emitting diodes (LED) lights against Staphylococcus aureus. against Streptococcus mutans, reaching 100\% mortality in these microorganisms [25].

Aminoglycosides are drugs with a broad spectrum of action against Gram-negative bacteria that have been widely used to treat severe infections [26]. However, an increasing number of bacterial strains have developed resistance to this class of antibiotics, mainly through the enzymatic inactivation mechanism [27]. The data of the present research indicated that the $\mathrm{OEOg}$, alone or in combination with LED lights, presented antibacterial effects that were comparable in magnitude to those observed for amikacin and gentamicin. This finding suggests that the essential oil, as well as phototherapy, have the potential to be used in the development of new therapies to treat infections caused by bacteria resistant to aminoglycosides. Additionally, the simultaneous association of amikacin with the oil and LED lights potentiated the action of this drug, suggesting that the combined treatment reverted, at least partially, the degree of observed resistance.
Ciprofloxacin and norfloxacin are antibacterial drugs belonging to the class of fluoroquinolones, which have a broad spectrum of action against both Gram-positive and Gram-negative microorganisms. Therefore, they are widely employed in the treatment of infections caused by bacteria resistant to other classes of antibiotics [28]. The resistance to fluoroquinolones occurs mainly through mechanisms that lead to changes in the access to target enzymes, preventing the drug from crossing the bacterial cell wall [29]. In the present study, the inhibition halos observed in the groups treated with both ciprofloxacin and norfloxacin were significantly larger than the halo formed by OEOg against the strains used in this research. However, the simultaneous association of these drugs with the oil and led lights varied considerably, suggesting that these combined therapies might not have a significant impact on the effectiveness of fluoroquinolones. In contrast, another study, using this same methodology, demonstrated that blue and red LED lights increased the inhibition halo of bacterial cultures treated with these drugs [30]. 
Nevertheless, these differences might be justified due to the use of different wavelengths and LED devices.

Accordingly, researchers evaluated the bactericidal action of LED devices with wavelengths ranging from 415 to $455 \mathrm{~nm}$ against $S$. aureus and $E$. coli, and concluded that the wavelength of $415 \mathrm{~nm}$ was more effective [31]. It has been demonstrated that the photoinduced antibacterial effect may involve the following mechanisms: Induction of biochemical changes in the bacterial cell membrane; inhibition of the cell respiration through a direct effect on the mitochondria; and induction of DNA damage, which could prevent cell division and inactivate enzymes associated with the cell metabolism [32].

The production of penicillinases is reported as the primary mechanism of resistance to penicillins. These enzymes catalyse the cleavage of the $\beta$-lactam ring of the structure of penicillin, inhibiting their antibacterial action [33]. While penicillin $\mathrm{G}$ is highly-active against Gram-positive cocci, it is susceptible to the effect of penicillinase. On the other hand, oxacillin has less potent antibacterial activity against penicillin G-sensitive bacteria but is resistant to penicillinase [34]. This study demonstrated that the activity of the OEOg was as potent as the action of these antibiotics, emphasising the antibacterial potential of this essential oil. Additionally, some combinations of LED lights and the OEOg significantly enhanced the activity of these antibiotics, confirming that combined therapies represent a promising alternative to combat bacterial resistance.

\section{Conclusion}

In conclusion, the essential oil obtained from O. gratissimum has an antibacterial effect whose potency varies according to the type of bacteria. The action of this oil can be enhanced by the association with LED lights and, both oil and LED lights potentiated the action of antibiotics under variable conditions, representing a promising alternative in the combat of bacterial resistance.

Nevertheless, further research is required to evaluate the safety and effectiveness of this combined therapy, as well as to its effects on bacterial cell physiology and structure. Moreover, these in vitro results encourage in vivo testing to investigate the potential use of modulation with OEOg and LED lights in the treatment of infectious skin diseases.

Author contributions: All authors have accepted responsibility for the entire content of this manuscript and approved its submission.

Research funding: This work was supported by Centro Universitário Dr. Leão Sampaio (Unileão) and Universidade Regional do Cariri (URCA).
Conflicts of interest statement: The authors declare no conflicts of interest regarding this article.

\section{References}

1. Bruning MCR, Mosegui GBG, Vianna CMM. The use of phytotherapy and medicinal plants in primary healthcare units in the cities of Cascavel and Foz do Iguaçu-Paraná: the viewpoint of health professionals. Cien Saude Colet 2012;17:2675-85.

2. Paula-Freire LIG, Molska GR, Andersen ML, de Araújo Carlini EL. Ocimum gratissimum essential oil and its isolated compounds (Eugenol and myrcene) reduce neuropathic pain in mice. Planta Med 2016;82:211-6.

3. Chimnoi N, Reuk-ngam N, Chuysinuan P, Khlaychan P, Khunnawutmanotham N, Chokchaichamnankit D, et al. Characterization of essential oil from Ocimum gratissimum leaves: antibacterial and mode of action against selected gastroenteritis pathogens. Microb Pathog 2018;118:290-300.

4. Suhr KI, Nielsen PV. Antifungal activity of essential oils evaluated by two different application techniques against rye bread spoilage fungi. J Appl Microbiol 2003;94:665-74.

5. Alcântara Júnior JP, Osuna JTA, Queiroz SROD, Rios AP. Ethnobotanical and ethnopharmacological surveys on medicinal plants from the municipality of Itaberaba-BA for cultivation and conservation. Sitientibus Ser Cienc Biol 2005;5:39-44.

6. Effraim KD, Jacks TW, Sadipo OA. Histopathological studies on the toxicity of Ocimum gratissimum leave extract on some organs of rabbit. Afr J Biomed Res 2003;6:21-5.

7. Lorenzi H, Matos FJ. Plantas medicinais no Brasil: nativas e exóticas, 2 ed. Plantarum:São Paulo; 2002.

8. Paton A. A synopsis of Ocimum L.(Labiatae) in Africa. Kew Bulletin 1992;47:403-35.

9. Coutinho HDM, Costa JGM, Lima EO, Falcão-Silva VS, SiqueiraJúnior JP. In vitro interference of Hyptis martiusii Benth. \& chlorpromazine against an aminoglycoside-resistant Escherichia coli. Indian J Med Res 2009;129;566-8.

10. Lira ALBC, Sá JD, Nogueira ILA, Medeiros MDC, Fernandes MICD, Vitor AF. Integridade da pele em idosos: revisão da literatura segundo as cartas de promoção da saúde. Cogitare Enfermagem 2012;17:767-74.

11. Lopes LRS, Kundman D, Duarte IAG. Avaliação da frequência de dermatoses no serviço ambulatorial de dermatologia Dermatosis frequency evaluation in the ambulatorial attendance of Dermatology. An Bras Dermatol 2010;85:264-6.

12. Moreira MC. Utilização de conversores eletrônicos que alimentam LEDs de alto brilho na aplicação em tecido humano e sua interação terapêutica. Santa Maria: Universidade Federal de Santa Maria, Doutorado em Engenharia Elétrica; 2009:165 p.

13. Silva JLM, Doimo G, Faria DP. Uso de ondas de alta frequência no tratamento de onicomicose: comunicação preliminar de três casos. An Bras Dermatol 2011;86:598-600.

14. Vinck EM, Cagnie BJ, Cornelissen MJ, Declercq HA, Cambier DC. Increased fibroblast proliferation induced by light emitting diode and low power laser irradiation. Laser Med Sci 2003;18: 95-9.

15. Matos FJA, Machado MIL, Craveiro AA, Alencar JW, Barbosa JM, Cunha EVL, et al. Essential oil of Mentha $\mathrm{x}$ villosa Huds. from Northeastern Brazil. J Essent Oil Res 1999;11:41-4. 
16. Adams RP. Identification of essential oil components by gas chromatography/mass spectrometry. Allured Publishing Corporation 2007:804 p.

17. Inouye S, Takizawa T, Yamaguchi H. Antibacterial activity of essential oils and their major constituents against respiratory tract pathogens by gaseous contact. J Antimicrob Chemother 2001;47:565-73.

18. Matias EFF, Alves EF, Santos BS, Souza CES, Ferreira JVA, Lavor AKLS, et al. Biological activities and chemical characterization of Cordia verbenacea DC. as tool to validate the ethnobiological usage. Evid Based Complement Alternat Med 2013; 2013:1-7.

19. Kong X, Liu X, Li J, Yang Y. Advance in pharmacological research of eugenol. Hubei Agricultural Sciences 2013;3:1-4.

20. Sokovic M, Glamoclija J, Marin PD, Brkic D, Van Griensven LJLD. Antibacterial effects of essential oils of commonly consumed medicinal herbs using an in vitro model. Molecules 2010; 15 : 7532-46.

21. Cheng SS, Liu JY, Chang EH, Chang ST. Antifungal activity of cinnamaldehyde and eugenol congeners against wood-rot fungi. Bioresour Technol 2008;99:5145-9.

22. Kong X, Liu X, Li J, Yang Y. Advances in pharmacological research of eugenol. Curr Opin Complement Alternat Med 2014;1:8-11.

23. Alo MN, Anyim C, Igwe JC, Elom M, Uchenna DS. Antibacterial activity of water, ethanol and methanol extracts of Ocimum gratissimum, Vernonia amygdalina and Aframomum melegueta. Adv Appl Sci Res 2012;3:844-8.

24. Demidova TN, Hamblin MR. Effect of cell-photosensitizer binding and cell density on microbial photoinactivation. Antimicrob Agents Chemother 2005;49:2329-35.

25. Bevilacqua IM, Nicolau RA, Khouri S, Brugnera Junior A, Teodoro GR, Zângaro RA, et al. The impact of photodynamic therapy on the viability of Streptococcus mutans in a planktonic culture. Photomed Laser Surg 2007;25:513-8.
26. Balakumar P, Rohilla A, Thangathirupathi A. Gentamicin-induced nephrotoxicity: do we have a promising therapeutic approach to blunt it?. Pharmacol Res 2010;62:179-86.

27. Jana S, Deb JK. Molecular understanding of aminoglycoside action and resistance. Appl Microbiol Biotechnol 2006;70: 140-50.

28. Souza MVN. New fluoroquinolones: a class of potent antibiotics. Mini-Rev Med Chem 2005;5:1009-117.

29. Endtz HP, Braak NV, Verbrugh HA, Belkum AV. Vancomycin resistance: status quo and quo vadis. Eur J Clin Microbiol Infect Dis 1999;18:683-90.

30. Pereira NLF, Aquino PEA, Júnior J. GAS, Cristo JS, Filho MAV, Moura FF, et al. In vitro evaluation of the antibacterial potential and modification of antibiotic activity of the Eugenia uniflora L. essential oil in association with led lights. Microb Pathog 2017; 110:512-8.

31. Lipovsky A, Nitzan Y, Gedanken A, Lubart R. Visible light-induced killing of bacteria as a function of wavelength: implication for wound healing. Laser Surg Med 2010;42:467-72.

32. Grebeňová D, Kuželová K, Smetana K, Pluskalová M, Cajthamlová H, Marinov I, et al. Mitochondrial and endoplasmic reticulum stress-induced apoptotic pathways are activated by 5-aminolevulinic acid-based photodynamic therapy in HL60 leukemia cells. J Photoch Photobio B 2003;69:71-85.

33. Cornaglia G, Giamarellou H, Rossolini GM. Metallo$\beta$-lactamases: a last Frontier for $\beta$-lactams?. Lancet Infect Dis 2011;11:381-93.

34. Brunton LL, Chabner BA, Knollmann BC. As bases farmacológicas da terapêutica de Goodman \& Gilman, 11 ed. Guanabara-koogan: Rio de Janeiro, 2010.

Supplementary material: Supplementary data to this article can be found online at https://doi.org/10.1515/znc-2020-0034. 